\title{
Neuroprotective effect of mitochondrial translocator protein ligand in a mouse model of tauopathy
}

Lauren H. Fairley ${ }^{1}$, Naruhiko Sahara², Ichio Aoki ${ }^{2}$, Bin Ji², Tetsuya Suhara², Makoto Higuchi ${ }^{2}$ and Anna M. Barron ${ }^{1,2^{*}}$ (D)

\begin{abstract}
Background: The translocator protein (TSPO) has been identified as a positron emission tomography (PET)-visible biomarker of inflammation and promising immunotherapeutic target for the treatment of Alzheimer's disease (AD). While TSPO ligands have been shown to reduce the accumulation of the toxic Alzheimer's beta-amyloid peptide, their effect on tau pathology has not yet been investigated. To address this, we analyzed the effects of TSPO ligand, Ro5-4864, on the progression of neuropathology in rTg4510 tau transgenic mice (TauTg).

Methods: Brain atrophy, tau accumulation, and neuroinflammation were assessed longitudinally using volumetric magnetic resonance imaging, tau-PET, and TSPO-PET, respectively. In vivo neuroimaging results were confirmed by immunohistochemistry for markers of neuronal survival (NeuN), tauopathy (AT8), and inflammation (TSPO, ionized calciumbinding adaptor molecule 1 or IBA-1, and complement component 1q or (1q) in brain sections from scanned mice.

Results: TSPO ligand treatment attenuated brain atrophy and hippocampal neuronal loss in the absence of any detected effect on tau depositions. Atrophy and neuronal loss were strongly associated with in vivo inflammatory signals measured by TSPO-PET, IBA-1, and levels of C1q, a regulator of the complement cascade. In vitro studies confirmed that the TSPO ligand Ro5-4864 reduces C1q expression in a microglial cell line in response to inflammation, reduction of which has been shown in previous studies to protect synapses and neurons in models of tauopathy.
\end{abstract}

Conclusions: These findings support a protective role for TSPO ligands in tauopathy, reducing neuroinflammation, neurodegeneration, and brain atrophy.

Keywords: Alzheimer's disease, Complement, Microglia, Neuroinflammation, Peripheral benzodiazepine receptor, Tau, TSPO, Translocator protein

\section{Background}

The mitochondrial translocator protein (TSPO) has been identified as an in vivo biomarker of neuroinflammation detectable via positron emission tomography (PET), and a potential immunotherapy target for the treatment of a

\footnotetext{
* Correspondence: barron@ntu.edu.sg

${ }^{1}$ Lee Kong Chian School of Medicine, Nanyang Technological University Singapore, Singapore 308232, Singapore

${ }^{2}$ National Institute of Radiological Science, Chiba City, Chiba Province 263-8555, Japan
}

range of neurodegenerative diseases including Alzheimer's disease (AD) [40]. In the AD brain, TSPO expression is upregulated in glia $[18,25]$, and has been implicated in a wide range of glial functions, including mitochondrial respiration, ATP production, migration, proliferation, phagocytosis, and secretion of cytokines [5, $15,29]$. In mouse models of $\mathrm{AD}$, we and others have shown that TSPO-targeted ligands are protective, reducing the accumulation of the toxic beta amyloid peptide $(\mathrm{A} \beta)$, which forms extracellular aggregates in the $\mathrm{AD}$

(c) The Author(s). 2021 Open Access This article is licensed under a Creative Commons Attribution 4.0 International License, which permits use, sharing, adaptation, distribution and reproduction in any medium or format, as long as you give appropriate credit to the original author(s) and the source, provide a link to the Creative Commons licence, and indicate if changes were made. The images or other third party material in this article are included in the article's Creative Commons licence, unless indicated otherwise in a credit line to the material. If material is not included in the article's Creative Commons licence and your intended use is not permitted by statutory regulation or exceeds the permitted use, you will need to obtain permission directly from the copyright holder. To view a copy of this licence, visit http://creativecommons.org/licenses/by/4.0/ The Creative Commons Public Domain Dedication waiver (http://creativecommons.org/publicdomain/zero/1.0/) applies to the data made available in this article, unless otherwise stated in a credit line to the data. 
brain $[6,16,32]$. However, to date, no study has investigated the effects of TSPO ligands on the other hallmark pathology of $\mathrm{AD}$, tauopathy, which is most closely associated with the progression of synaptic and neuronal loss and clinical progression of the disease $[2,13]$.

Tauopathy is comprised of neuronal intracellular aggregates of abnormally phosphorylated tau, a cytoskeletal protein that interacts with microtubules [27]. Tauopathy induces synaptic loss, neuronal dysfunction and death, and although the mechanisms underlying tau-induced neurotoxicity continue to be debated, inflammation is emerging as a key player $[35,38]$. Because we have previously demonstrated that TSPO ligands reduce neuroinflammation and reverse $A \beta$ pathology in a mouse model of $\mathrm{AD}$ [6], the present study aims to evaluate the effect of the well-characterized TSPO ligand Ro5-4864 (Ro5) on inflammation and neurodegeneration in a mouse model of tauopathy. Here, we use rTg4510 tau transgenic mice (TauTg) expressing a P301L mutant human tau gene (P301L) [41]. These TauTg mice exhibit aggressive neuropathology in cortical and hippocampal regions, developing TSPO-positive gliosis, which can be detected by PET and is closely associated with the progression of tau deposition and brain atrophy $[8,26]$. We investigate whether treatment with Ro5 attenuates neuroinflammation, tau pathologies, and brain atrophy using clinically translatable, non-invasive neuroimaging approaches including positron emission tomography (PET) and volumetric magnetic resonance imaging (MRI). Inflammation was assessed by PET using the recently described TSPO tracer, 2-[5-(4- ${ }^{18}$ F-fluoroethoxy-2-oxo-1, 3-benzoxazol-3(2H)-yl)-N-methyl-N-phenylacetamide]

$\left({ }^{18} \mathrm{~F}\right.$-FEBMP) [45], while tau aggregates were assessed using the tau-PET tracer, ${ }^{11} \mathrm{C}-\mathrm{PBB} 3$ [34]. These findings will provide the preclinical foundation for the pursuit of TSPO-targeted therapeutics in AD.

\section{Methods}

\section{Animals and treatments}

All experimentation was approved by the Institutional Animal Care and Use Committee of the National Institutes for Quantum and Radiological Science and Technology, where experimental mice were bred and maintained in Specific Pathogen Free conditions with food and water available ad libitum. Tau transgenic rTg4510 mice (TauTg) expressing mutant human tau $\left(4 \mathrm{R} 0 \mathrm{~N}\right.$ tau $\left._{\mathrm{P} 301 \mathrm{~L}}\right)$ under the tetracycline controlled repressible promoter expressing both the mutant tau transgene (4R0N tauP301L) and the tetracycline controlled transactivator were used (Ramsden et al. [37]). NonTg mice were littermates that did not express either transgene. Mice were genotyped by the analysis of DNA isolated from tail clips. At 18-20 weeks of age, TauTg mice were injected (i.p.) with either vehicle $(2.5 \%$
DMSO, $1 \%$ tween in saline; $n=3$ male and 3 female) or TSPO-ligand Ro5 ( $3 \mathrm{mg} / \mathrm{kg}, n=3$ male and 4 female) once weekly for a period of 4 months (16 doses). NonTg controls were injected with a vehicle for comparison ( $n$ $=6$ male and 6 female). Since one female vehicle-treated TauTg mouse died in the third week of treatment, and an age-matched female littermate was enrolled in the study as a replacement, no baseline scan data were collected for this mouse. Baseline volumetric MRI, tauPET, and TSPO-PET were conducted in the first month of the study. In the final month of the study, volumetric MRI, tau-PET, and TSPO-PET was re-evaluated (completion scan), then tissues were collected at $\sim 9$ months of age. TSPO-PET was carried out after a 1-week washout period following Ro5 administration. One nonTg mouse was not scanned for MRI at baseline, or ${ }^{11} \mathrm{C}$ PBB3 or ${ }^{18} \mathrm{~F}$-FEBMP at the completion time point due to the failure of tail vein catheterization. Data from control groups were used for the evaluation of the performance of a mitochondrial complex-I PET tracer, with scans conducted in mice from all groups at 2 and 7-8 months of age, this data has been reported elsewhere [8]. For tissue collection, mice were anesthetized $(50 \mathrm{mg}$ sodium pentobarbital/kg body weight, i.p.) and intracardially perfused with ice-cold, sterile saline. Brains were collected, frozen on dry ice, and stored at $-80{ }^{\circ} \mathrm{C}$ until analysis.

\section{In vivo MRI and PET imaging}

In vivo MRI and PET scans were carried out on isoflurane-anesthetized mice $(3 \%$ induction, $1.5-2 \%$ maintenance) according to previously described methods [8]. Briefly, transaxial T2-weighted fast spin-echo MR images using a rapid acquisition with relaxation enhancement sequence were acquired using a 7.0-T horizontal MRI scanner (Magnet: $40 \mathrm{~cm}$ bore, Kobelco \& JASTEC, Japan; Console: Avance-I, Bruker Biospin, Germany) with a volume coil for transmission (Bruker BioSpin) and a quadrature surface coil for reception (Rapid Biomedical). Manual segmentation to define anatomical regions of interest (cortex, hippocampus, and cerebellum) was performed with reference to the mouse brain atlas of Paxinos and Franklin using the PMOD software (version 3.4; PMOD Technologies, Inc., Zurich, Switzerland).

For PET studies, ${ }^{11} \mathrm{C}$-PBB3 and ${ }^{18} \mathrm{~F}$-FEBMP were prepared according to previously published methods [34, $45,47]$. The molar activity of the end-product was 61.1 $\pm 7.5 \mathrm{GBq} / \mu \mathrm{mol}$ and $290.5 \pm 1.0 \mathrm{GBq} / \mu \mathrm{mol}$ for ${ }^{11} \mathrm{C}$ PBB3 and ${ }^{18}$ F-FEBMP, respectively. Anesthetized mice were administered with either ${ }^{11} \mathrm{C}$-PBB3 $(30.5 \pm 0.85$ $\mathrm{MBq})$ or ${ }^{18} \mathrm{~F}$-FEBMP $(34.2 \pm 0.7 \mathrm{MBq})$ via tail vein catheter while in a microPET Focus 220 animal scanner (Siemens Medical Solutions). A $90 \mathrm{~min}\left({ }^{18} \mathrm{~F}\right.$-FEBMP) or 60 
min $\left({ }^{11} \mathrm{C}\right.$-PBB3) 3D list mode emission scan was started simultaneously with radioligand injection. List-mode data were sorted into 3D sinograms then Fourier rebinned into $2 \mathrm{D}$ sonograms with time frame reconstruction of $1 \mathrm{~min} \times 4$ frames, $2 \mathrm{~min} \times 8$ frames, and 5 min $\times 14$ frames. Summation images were reconstructed with maximum a posteriori reconstruction, and dynamic images were reconstructed with filtered back-projection using a 0.5-mm Hanning filter. Dynamic PET images were merged to the individual MRI data by an experimenter blinded to treatment conditions, and tracer uptake in each VOI was estimated as the percent of injected dose per $\mathrm{mL}(\% \mathrm{ID} / \mathrm{mL})$. Because the cerebellum is unaffected by pathology, the cerebellum was used as a reference for calculation of the target-to-reference ratio $[8,9]$.

\section{Immunohistochemistry}

Fresh frozen hemibrains were sectioned in the sagittal plane at $20 \mu \mathrm{m}$ by a cryostat. Sections were fixed in $4 \%$ paraformaldehyde and labeled using antibodies directed against ionized calcium-binding adaptor molecule-1 (IBA-1, rabbit polyclonal, WAKO), NeuN (Abcam ab177487), C1q (Abcam ab182451), AT8 (mouse monoclonal, Endogen), and TSPO (rabbit monoclonal, Abcam). All staining, imaging, and analysis parameters were maintained consistently between samples for each marker. Images were captured using a fluorescence microscope/digital camera (BZ-X700, Keyence) and analyses were performed in an experimenter-blinded manner using ImageJ. Images were background subtracted using rolling ball radius of 50 pixels prior to analysis or use in figures. For measurement of CA1 width, images of NeuN staining in the CA1 region were captured at $\times 20$ magnification and three lines per image were drawn across the CA1 region at equidistant intervals using the straight line tool, and the average length in pixels was measured, as previously described [17]. NeuN staining and CA1 width analysis was repeated twice on nonconsecutive sections for each animal and an average used for analysis of group-wise differences. For quantification of IBA-1 and TSPO, an image of the frontal cortex and hippocampus was captured in two sections per animal and after background subtraction, 8-bit images were thresholded at 25-255 for IBA-1 or 20-255 for TSPO and percent area measured. For quantification of AT8 and C1q, the entire section was imaged using the automated image stitching and regions of interest were manually drawn around the hippocampus and cortex using anatomical landmarks. Images were thresholded to create a binary image identifying positive and negative immunolabeling, and the percent area of positive labeling in the regions of interest measured, as previously described [9]. Brightness is linearly adjusted in images presented in figures, with adjustment applied equally to all samples.

\section{Western blot}

Western blotting was performed as previously described (Sahara et al. [42]). Briefly, cortical and hippocampal regions were combined and homogenized in Tris-buffered saline (TBS, $50 \mathrm{mM}$ Tris/hydrochloric acid, $\mathrm{pH}$ 7.4, 274 $\mathrm{mM}$ sodium chloride, $5 \mathrm{mM}$ potassium chloride; $\times 10$ $\mathrm{vol} /$ tissue wet weight) containing $1 \%$ protease inhibitor mixture (Sigma, St. Louis, MO), 1\% phosphatase inhibitor cocktail I and II (Sigma), and $1 \mathrm{mM}$ phenylmethylsulfonyl fluoride. Homogenates were centrifuged at 27, $000 \times g$ for $20 \mathrm{~min}$ at $4{ }^{\circ} \mathrm{C}$, and the supernatant was diluted in sodium dodecyl sulfate-sample buffer containing $\beta$-mercaptoethanol $(2.5 \%)$ and heat-treated at $55{ }^{\circ} \mathrm{C}$ for $15 \mathrm{~min}$. Samples were separated by gel electrophoresis in $10 \%$ Tris-glycine sodium dodecyl sulfatepolyacrylamide gels (Nacalai Tesque) and transferred to nitrocellulose membranes (BioRad Laboratories, Hercules, CA). Membranes were incubated with a blocking solution containing 5\% skim milk and $0.1 \%$ Triton $\mathrm{X}-100$ in TBS for $30 \mathrm{~min}$. Membranes were then probed with anti-Tau12 (Invitrogen, Cat \#MAB2241) and glyceraldehyde-3-phosphate-dehydrogenase (GAPDH, Sigma-Aldrich, Cat \# MAB374) antibodies overnight at 4 ${ }^{\circ} \mathrm{C}$, followed by anti-mouse Immunoglobulin G (1:5000; Jackson ImmunoResearch) for $1 \mathrm{~h}$ at RT. Chemiluminescent signals were detected using an enhanced chemiluminescence system (ECL PLUS kit; PerkinElmer), and immunoreactivity was visualized by a computer-linked LAS-4000 BioImaging Analyzer System (Fujifilm, Tokyo, Japan). Band intensities were quantified using the NIH ImageJ software. To compare tau levels across different mouse brains, the relative amount of tau protein was normalized against GAPDH levels. All blots were repeated twice, and the average of two blots was calculated.

\section{Cell culture and flow cytometry}

The immortalized murine microglial BV-2 cell line was grown and maintained in Dulbecco's modified Eagle serum (DMEM) containing 10\% fetal bovine serum and $1 \%$ penicillin-streptomycin at $37{ }^{\circ} \mathrm{C}$ in $5 \% \mathrm{CO}_{2}$. BV-2 cells were collected, and $1 \times 10^{5}$ cells were plated in 6well plates overnight. The medium was removed, and cells were stimulated with either vehicle ( $1 \%$ ethanol) or 10nM Ro5 (Sigma Aldrich, C5174) diluted in DMEMHam's F12 containing 1\% penicillin-streptomycin for 24 $\mathrm{h}$, followed by stimulation with $100 \mathrm{ng} / \mathrm{ml}$ LPS or vehicle for $2 \mathrm{~h}$. Cells were then trypsinized and centrifuged, and the resulting pellet was fixed in $4 \%$ paraformaldehyde for $10 \mathrm{~min}$, followed by permeabilization with $0.1 \%$ Triton $\mathrm{X}-100$ in phosphate-buffered saline for $5 \mathrm{~min}$. C1q 
was labeled using an anti-C1q antibody (Abcam, ab182451), and fluorochrome-conjugated anti-rabbit secondary antibody (Invitrogen, A11034), and fluorescence was detected by flow cytometry. Mean fluorescent intensity was analyzed using the FlowJo software (Tree Star, Ashland, OR).

\section{Data analysis}

Data were analyzed using the Statistical Package for Social Sciences (SPSS: version 25; SPSS Inc., IL, USA), Primer version 6 (PRIMER-E, Auckland, New Zealand), and the $\mathrm{R}$ environment ( $\mathrm{R}$ Core Team. $\mathrm{R}$ [39]) with the lme4 package (Bates, Maechler, Bolker, and Walker [10]) and plots were generated using GraphPad Prism 8.2.1 (GraphPad Software).

Homoscedasticity and normality was assessed using diagnostic residual plots, Levine's, and Shapiro-Wilk tests. Parametric data were analyzed by ANOVA. MRI and PET data was analyzed using a $3 \times 2 \times 3$ mixed-model ANOVA including brain region (CTX, HIP, CB) and treatment time point (baseline $=5$ months; completion $=9$ months) as within-subject factors and group (nonTg, TauTg+ Veh, TauTg + Ro5) as the between subjects factor. AT 8 was analyzed by a $2 \times 3$ mixed-model ANOVA, including brain region (CTX and HIP) as the withinsubjects factors and treatment group (nonTg, TauTg + Veh, TauTg + Ro5) as the between subjects factor. Hippocampal width measured by NeuN was analyzed by one-way ANOVA. Significant factors or interactions were further explored using least squares difference post-hoc comparisons. Associations between variables were evaluated using Spearman's rank correlation coefficient. The effect of treatment on inflammatory markers TSPO, IBA-1, and C1q measured by immunoreactivity was analyzed by permutational multivariate analysis of variance (PERMANOVA), including treatment group and region as fixed factors. Between sample similarity was computed based on Euclidean distances, and analysis was based on 9999 unrestricted permutations of raw data using type III (partial) sum of squares, and the resulting $F$ statistic is quoted as "pseudo-F" and $p$ statistic " $p_{\text {perm }}$ " [1]. PERMANOVA analysis of inflammatory markers was followed by distance-based redundancy analysis (dbRDA) to explain the observed differences in the inflammatory response of the treatment groups. $\mathrm{C} 1 \mathrm{q}$ flow cytometry data was analyzed by one-way ANOVA.

\section{Results}

TSPO ligand Ro5-4864 attenuates brain atrophy and neuronal loss in TauTg mice

To evaluate the effect of TSPO ligand Ro5 treatment on brain atrophy, cortical, hippocampal, and cerebellar volumes were measured longitudinally in vivo by volumetric MRI at baseline (5 months) and following treatment
(9 months; Fig. 1a). Mixed ANOVA revealed an interaction between group, treatment time point, and brain region on brain volume $\left(F_{(2,20)}=12.322, p<0.001\right.$; Fig. 1a-d). At baseline, no significant differences in brain volume were observed between groups (hippocampus: nonTg vs TauTg + veh $p=0.426$; cortex: nonTg vs TauTg + veh $p=0.57$ ); however, by 9 months of age TauTg mice showed reduced hippocampal $(p<0.001$, Fig. 1b) and cortical ( $p<0.001$, Fig. 1c), but not cerebellar volumes $(p=0.523$; Fig. 1d) compared to nonTg mice. While nonTg mice exhibited a modest $10-15 \%$ increase in hippocampal and cortical volumes between 5 and 9 months, vehicle-treated TauTg mice exhibited a loss of more than $25 \%$ of hippocampal and $20 \%$ of cortical volume over this same duration. Treatment with Ro5 markedly attenuated atrophy between 5 and 9 months, halving both hippocampal and cortical volumetric loss compared to vehicle-treated TauTg mice (hippocampus: $p=0.005$; cortex: $p=0.021$, Fig. $1 \mathrm{~b}, \mathrm{c}$ ).

To corroborate in vivo volumetric MRI findings, neuronal viability was assessed in sections from scanned mice at 9 months of age by immunohistochemistry for the neuronal marker, NeuN (Fig. 3e, f). A significant main effect of group was observed (one way ANOVA; $F_{(2,22)}$ $=23.393 p<0.001)$. Consistent with volumetric MRI data, hippocampal CA1 pyramidal layer thickness was reduced in TauTg compared to nonTg mice (CA1 width: nonTg vs TauTg + veh $p<0.001$; nonTg vs TauTg + $\operatorname{Ro5} p=0.003)$. However, a neuroprotective effect of Ro5 treatment was observed, with a modest increase in CA1 width in TauTg mice treated with Ro5 compared to vehicle ( $p=0.028$, Fig. 1f).

\section{No benefit of TSPO ligand Ro5-4864 on tau deposition in TauTg mice}

To determine if Ro5 treatment attenuated neuronal loss through effects on tau pathogenesis, tau accumulation was measured longitudinally in vivo by ${ }^{11} \mathrm{C}$-PBB3-PET at baseline $(5 \mathrm{~m})$ and following treatment $(9 \mathrm{~m}$, Fig. $2 \mathrm{a})$. Mixed ANOVA revealed a significant interaction between group, treatment time point, and region on ${ }^{11} \mathrm{C}$ PBB3 uptake $\left(F_{(2,17)}=5.795, p=0.012\right.$; Fig. 2b). At baseline, increased ${ }^{11} \mathrm{C}-\mathrm{PBB} 3$ uptake was observed in TauTg mice compared to nonTg mice in the hippocampus (TauTg + veh $p=0.017$; TauTg $+\operatorname{Ro5} p=0.005$ ), but not cortex (TauTg + veh: $p=0.913$; TauTg $+\operatorname{Ro} 5 p=$ 0.885). At 9 months of age, increased ${ }^{11} \mathrm{C}$-PBB3 uptake was observed in TauTg mice treated with both vehicle and Ro5 in the hippocampus (nonTg v TauTg + Veh $p$ $=0.017$; nonTg $\mathrm{v}$ TauTg $+\operatorname{Ro5} p=0.001)$ and cortex (nonTg v TauTg + Veh $p=0.002$; nonTg v TauTg + Ro5 $p<0.001$; Fig. 2a-e). No differences between vehicle- and Ro5-treated TauTg mice were observed (hippocampus: $p=0.239$; cortex: $p=0.566$; Fig. $2 \mathrm{~d}$, e). 


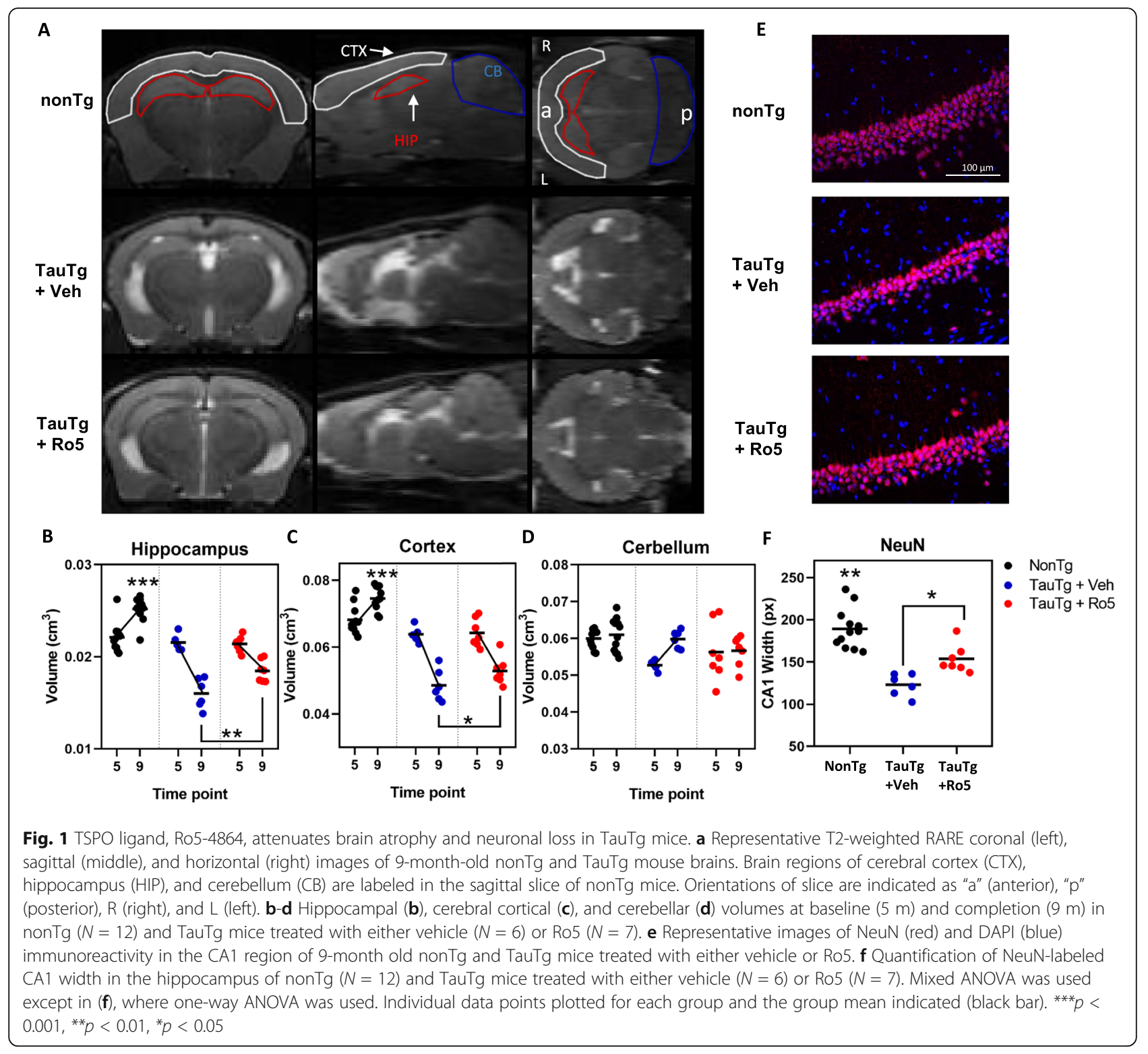

In vivo tau PET findings were confirmed in sections from scanned mice by immunohistochemistry using the phosphorylated tau antibody, AT8 (Fig. 2f, g). No differences in AT8 immunoreactivity between regions was observed (mixed ANOVA; $F_{(1,10)}=1.593, p=0.235$ ) and, consistent with ${ }^{11} \mathrm{C}$-PBB3 signals, no difference in AT8 immunoreactivity was observed between vehicle and Ro5treated TauTg mice $\left(F_{(1,10)}=0.794, p=0.394\right.$; Fig. 2f, g). No AT8 immunoreactivity was observed in nonTg mice. To determine if Ro5 had any effect on expressions of tau proteins, the total tau was assessed in TBS-extractable fractions from combined cortical and hippocampal homogenate by western blot using antibodies directed against $\mathrm{N}$-terminus of human tau (Tau 12). No difference in total tau levels were observed between vehicle- and Ro5-treated TauTg mice $\left(t_{(11)}=-0.542, p=0.226\right.$; Fig. $\left.2 \mathrm{~h}, \mathrm{i}\right)$.
TSPO ligand attenuates neuroinflammation in TauTg mice The effect of TSPO ligand treatment on in vivo TSPO signals were measured longitudinally by PET using ${ }^{18} \mathrm{~F}$ FEBMP, comparing baseline (5 months) and posttreatment time points (9 months, Fig. 3). An interaction between group and treatment time point was observed on ${ }^{18}$ F-FEBMP signals in the hippocampus and cortex (Mixed ANOVA, $F_{(2,20)}=12, p<0.001$ ). At baseline, no differences in ${ }^{18} \mathrm{~F}$-FEBMP signals were observed between nonTg and TauTg mice (nonTg vs TauTg + veh: $p=$ 0.281; nonTg vs TauTg + Ro5: $p=0.2$ ). At 9 months of age, ${ }^{18} \mathrm{~F}$-FEMBP signals were significantly increased in vehicle treated TauTg mice compared to both Ro5 treated TauTg mice $(p=0.029)$ and nonTg mice $(p<$ 0.001, Fig. 3d, e). Hippocampal TSPO-PET signals at study completion were strongly associated with 


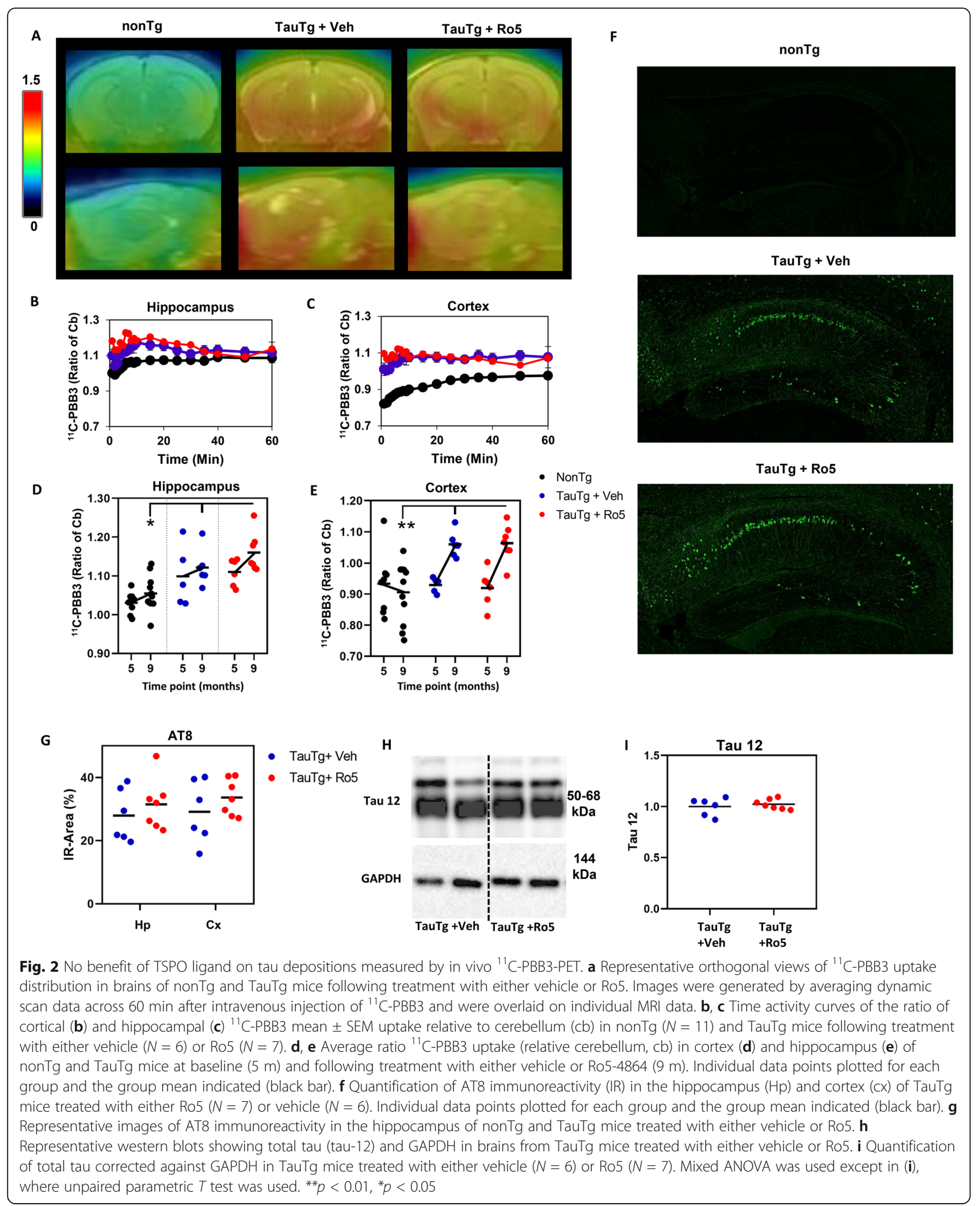




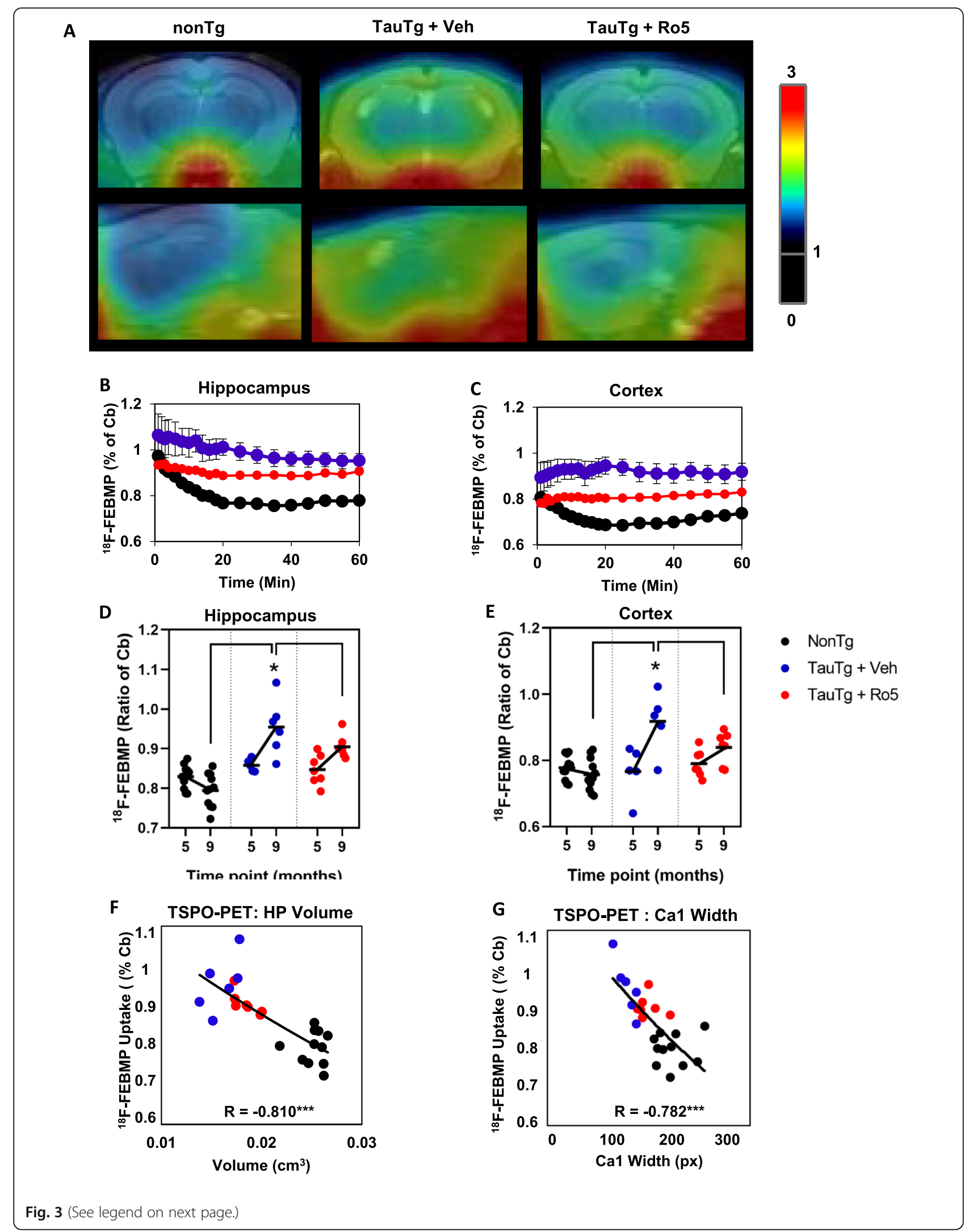




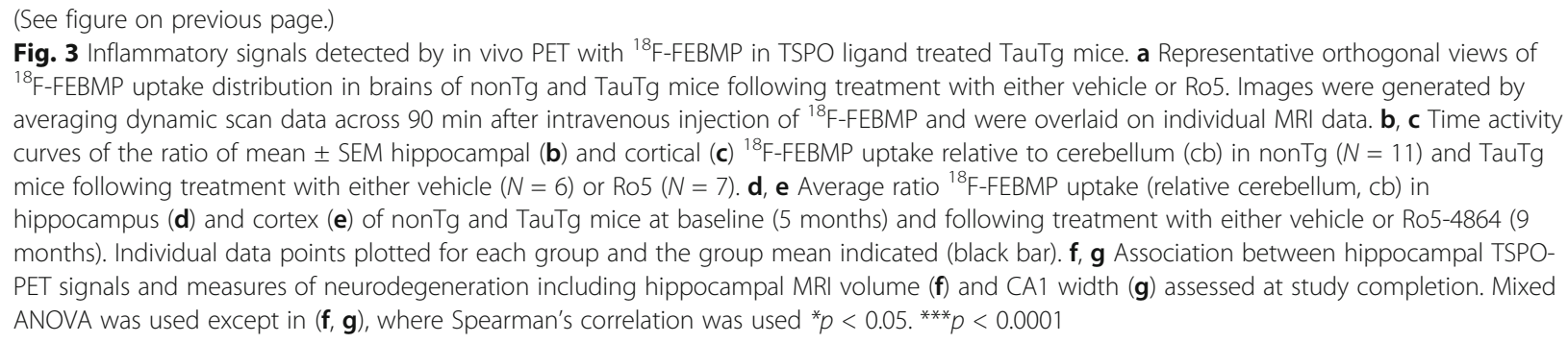

measures of neurodegeneration including atrophy assessed by MRI $(r=-0.810, p<0.0001$; Fig. 3f $)$ and CA1 width $(r=-0.782, p<0.0001$; Fig. $3 g)$.

In vivo neuroinflammatory signals measured by TSPO-PET were corroborated in sections from scanned mice by immunohistochemistry for inflammatory markers including TSPO, the microglial marker IBA-1, and regulator of the complement cascade, complement component C1q (Fig. 4a). Inflammatory marker immunoreactivity was correlated with in vivo TSPO-PET signals in the hippocampus (TSPO: $r=0.726, p<0.0001$; IBA-1: hippocampus $r=0.754, p<0.0001$; C1q: $r=$ 0.572, $p=0.003$; Suppl. Fig. 1A-C). Multivariate analysis of TSPO, IBA-1, and C1q immunoreactivity revealed significant differences in inflammatory markers across groups $\left(\right.$ PERMANOVA, pseudo- $F_{(2,49)}=19.24, p_{\text {perm }}=$ $0.0001)$, with vehicle-treated TauTg mice significantly different compared to both nonTg $\left(p_{\text {perm }}=0.0001\right)$ and Ro5-treated TauTg groups $\left(p_{\text {perm }}=0.03\right)$. Mean levels of TSPO, IBA-1, and C1q were increased in TauTg compared to nonTg mice, with levels of IBA-1 and C1q increasing over tenfold in vehicle treated TauTg compared to nonTg mice. Treatment of TauTg mice with Ro5 reduced mean levels of the three inflammatory markers measured, although a large amount of individual variability within groups was noted (Fig. 4b-d). Distancebased redundancy analysis (dbRDA) indicated that most $(75 \%)$ of the variation between groups in inflammatory markers was closely correlated with C1q (0.998). Measures of neurodegeneration in both the hippocampus and cortex were negatively associated with inflammatory markers, particularly IBA-1 and TSPO (Table 1).

Since C1q is almost exclusively produced by microglia in the brain $[20,21]$, we examined the effect of Ro5 on C1q levels in the immortalized microglial cell line, BV2, to determine if Ro5 attenuated C1q levels in the TauTg mice by affecting the microglial inflammatory response. BV2 microglial cells were pretreated with either Ro5-4864 or vehicle, then stimulated with LPS to induce inflammation. LPS markedly increased C1q levels, an effect that was inhibited by Ro5 pre-treatment (ANOVA, $F_{(2,7)}=24.825$, $p<0.001$; Veh vs Veh + LPS: $p<0.001$; Veh + LPS vs Ro5 + LPS: $p=0.028 ; n=3$-4/group in each experiment, experiment repeated 3 times; Fig. 4e-g).

\section{Discussion}

Here, we demonstrate that the TSPO ligand Ro5 is protective in a mouse model of tauopathy, reducing markers of neurodegeneration, which was strongly associated with inflammatory signals measured in vivo and in endpoint tissues. Further, we demonstrate the potential usefulness of the recently described TSPO-PET tracer, ${ }^{18} \mathrm{~F}$ FEBMP, for evaluating efficacy of novel immunotherapeutics for $\mathrm{AD}$. Taken together, these findings indicate that TSPO is a promising target for the development of biomarker and immunomodulatory strategies in $\mathrm{AD}$.

In the current study, we observed a marked effect of Ro5 treatment on neurodegeneration in a model of tauopathy, with atrophy and neuronal loss reduced by half. The magnitude of this neuroprotective effect is similar to that observed through complete repression of the tau transgene using doxycycline treatment from 4 months of age [12]. Although the mechanism of neuroprotection in the current study is not clear, we propose that the neuroprotective effect was downstream of tau accumulation since we did not observe any significant benefit on measures of tauopathy. However, we cannot rule out that the neuroprotective effect of TSPO ligand treatment may have been mediated through non-tau-related neuronal death mechanisms since recent studies have demonstrated that neuronal loss in this TauTg model is not solely the result of mutant tau overexpression, but disruption and partial deletion of a number of other genes at the insertional site of the tau transgene also contributes [22].

Since TSPO is highly expressed in microglia and has been identified as an immunomodulator, we hypothesized that Ro5 may have mediated neuroprotection via action on microglia. Previous studies have demonstrated TSPO ligands inhibit detrimental inflammatory profiles in microglia, including in response to LPS $[14,46]$, while in vivo neuroprotective effects linked to immune modulation by TSPO ligands have been described in other models of injury including a model of Parkinson's disease [23] and retinal degeneration [43]. Consistent with this hypothesis, here we found that markers of neuroinflammation were strongly associated with degree of atrophy and neuronal loss. Further, we demonstrated in vitro that the TSPO ligand Ro5 acts on immortalized 


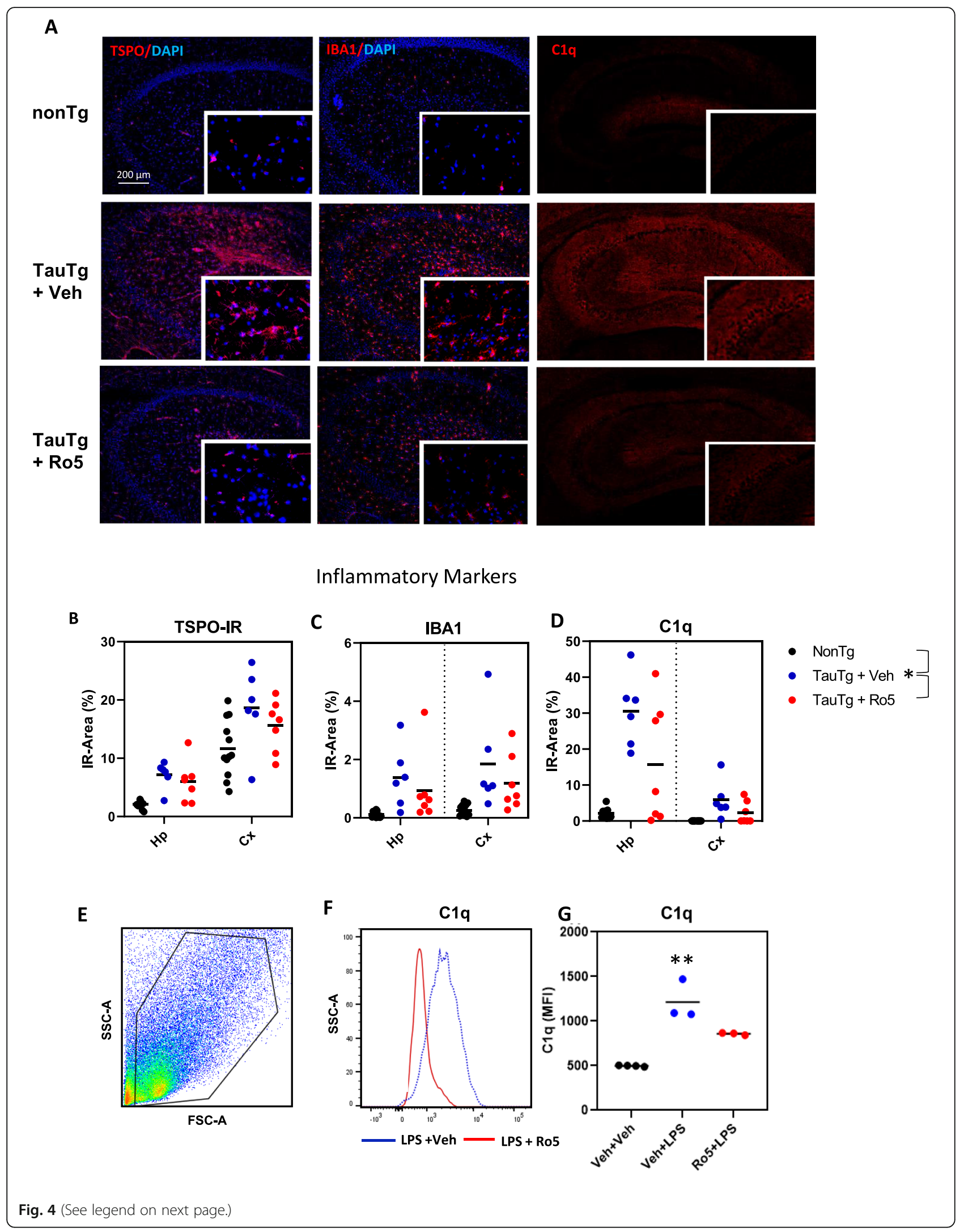


(See figure on previous page.)

Fig. 4 TSPO ligand reduces hippocampal neuroinflammation in TauTg mice. a Representative images of TSPO (left panel), IBA-1 (middle panel), and Clq (right panel) immunoreactivity in the hippocampus of 9-month-old nonTg, and TauTg mice treated with either vehicle or Ro5. Inset shows digitally magnified view of image. b-d Quantification of immunoreactivity of the inflammatory markers, TSPO (b), IBA-1 (c), and C1q (d) in the hippocampus and cerebral cortices of nonTg $(N=12)$ and TauTg mice treated with either $\operatorname{Ro5}(N=7)$ or vehicle $(N=6)$. Individual data points plotted for each group and the group mean indicated (black bar). PERMANOVA, ${ }^{*} p_{\text {perm }}<0.03$. e Representative gating (left) and flow cytometry histogram of C1q levels (right) in unstimulated BV2 cells (black) or following stimulation with LPS after pretreatment with either vehicle (blue) or Ro5 (red). MFI, mean fluorescent intensity. SSC, side scatter. FSC, forward scatter. f Quantification of C1q binding in BV2 cells ( $n=3-4$ / group/experiment, single experiment shown, experiment replicated 3 times). One-way ANOVA. ${ }^{*} p=0.003$

microglial cell lines to reduce $\mathrm{C} 1 \mathrm{q}$ expression in response to inflammation. $\mathrm{C} 1 \mathrm{q}$ is the recognition component that initiates the classical complement cascade system, identified as a marker of detrimental inflammatory phenotypes associated with LPS-induced inflammatory programs in microglia and is upregulated in TauTg mice $[19,34]$. Future studies could further investigate interactions between TSPO, C1q, and tau-induced neuronal death.

Although TSPO is highly expressed in activated microglia [28, 33], recent studies have also demonstrated that neurons express TSPO, albeit at low levels, and may too be a direct target for TSPO therapeutics [7, 36]. Further, recent studies have demonstrated that TSPO ligands can protect cultured neurons against tau and $A \beta$ induced toxicity by promoting mitochondrial fitness [24, 31]. Future studies could use conditional TSPO knockout models to address the relative neuronal versus microglial cellular targets of TSPO therapeutic effects in models of neurodegeneration, which may provide more insight into mechanism of neuroprotection.

Interestingly, despite the protective effect of Ro5 against atrophy and neurodegeneration, no benefit was observed on tau depositions. It is possible the beneficial effect of Ro5 might be underestimated due to an improved survival of tangle-bearing neurons following the treatment. Further, other studies suggest that only the most robust inhibition of microglia is effective in modulating tau pathology. For instance, previous studies in TauTg mice have found that while near-complete depletion of microglia successfully reduced tauopathy [3], partial depletion of microglia had no effect on tauopathy [11]. Therefore, higher or more frequent dosing may be required to alter tauopathy with TSPO ligands. Additionally, immunomodulatory strategies may be more effective when initiated early in the disease process. For example, microglial depletion protected against neurodegeneration and tau accumulation when treatment was started prior to the onset of neuronal degeneration [44]; however, other studies that initiated treatment after neuronal loss had begun reported no protective effects [11]. While our current study provides proof-inprinciple that TSPO-targeted drugs are protective against tau-induced neurodegeneration, future studies could address optimal dosing and early versus late intervention strategies.

Of note, other studies targeting microglial function have also reported beneficial neuroprotective effects in the absence of altered tauopathy. For example, tyrosine motif binding protein (TYROBP) knockout resulted in reduced $\mathrm{C} 1 \mathrm{q}$, improved synaptic function and learning and memory outcomes, despite worsening of tauopathy

Table 1 Markers of neurodegeneration strongly associated with inflammatory markers. Spearman's correlation between inflammatory markers, IBA-1, TSPO, and C1q, measured by immunoreactivity and measures of neurodegeneration assessed by MRI volume and NeuN immunoreactivity in hippocampus (Hp) and cortex (CX)

\begin{tabular}{|c|c|c|c|c|}
\hline \multirow[t]{2}{*}{ Region } & \multirow{2}{*}{$\begin{array}{l}\text { Inflammatory } \\
\text { marker }\end{array}$} & \multirow{2}{*}{$\begin{array}{l}\text { Neurodegeneration } \\
\text { marker }\end{array}$} & \multicolumn{2}{|c|}{ Correlation } \\
\hline & & & $r$ & $p$ \\
\hline \multirow[t]{6}{*}{$\mathrm{Hp}$} & |BA-1 & MRI volume & -0.792 & $<0.0001$ \\
\hline & TSPO & & -0.833 & $<0.0001$ \\
\hline & $\mathrm{Clq}$ & & -0.538 & 0.005 \\
\hline & $\mid \mathrm{BA}-1$ & CA1 Width & -0.679 & $<0.0001$ \\
\hline & TSPO & & -0.772 & $<0.0001$ \\
\hline & $\mathrm{Clq}$ & & -0.588 & 0.002 \\
\hline \multirow[t]{3}{*}{$C x$} & $\mid \mathrm{BA}-1$ & MRI volume & -0.702 & $<0.0001$ \\
\hline & TSPO & & -0.538 & 0.006 \\
\hline & $\mathrm{Clq}$ & & -0.795 & $<0.0001$ \\
\hline
\end{tabular}


[4]. TYROBP has been identified as a key regulator of the complement family in late-onset AD [48] and is implicated in the differentiation of the protective diseaseassociated microglia (DAM) phenotype [30]. These findings suggest microglial functions affecting tau accumulation versus synaptic loss are not necessarily overlapping, and importantly, highlights that although damaged by tauopathy, synapses and neurons remain functional if they are spared from neuronal death.

\section{Conclusions}

Here, we report the first evidence to date that TSPO ligands exert protective effects in a mouse model of tauopathy, attenuating brain atrophy and reducing neuroinflammation. While many new generation, safe TSPO ligands have been developed for in vivo PET imaging in humans, our findings suggest these ligands may also have therapeutic potential for the treatment of $\mathrm{AD}$.

\section{Abbreviations \\ AB: Beta amyloid; AD: Alzheimer's disease; CA1: Cornu Ammonis-1; C1q: Complement component 1q; ${ }^{11} \mathrm{C}-\mathrm{PBB} 3: 2-((1 \mathrm{E}, 3 \mathrm{E})-4-(6-((11) \mathrm{C}-$ methylamino)pyridin-3-yl)buta-1,3-dienyl) benzo[d]thiazol-6-ol; DAM: Disease- associated microglia; dbRDA: Distance-based redundancy analysis; DMEM: Dulbecco's modified Eagle serum; DMSO: Dimethyl sulfoxide; ${ }^{18} \mathrm{~F}-$ FEBMP: 2-[5-(4- ${ }^{18}$ F-fluoroethoxy-2-oxo-1,3-benzoxazol-3(2H)-yl)-N-methyl-N- phenylacetamide]; GAPDH: Glyceraldehyde-3-phosphate-dehydrogenase; IBA- 1: Ionized calcium-binding adaptor molecule 1; i.p.: Intraperitoneal; MRI: Magnetic resonance imaging; NonTg: Non-transgenic; PERM ANOVA: Permutational Multivariate Analysis of Variance; PET: Positron emission tomography; Ro5: Ro5-4864; TauTg: Tau transgenic; TBS: Tris buffered saline; TSPO: Translocator protein; TYROBP: Tyrosine motif binding protein; Veh: Vehicle}

\section{Supplementary Information}

The online version contains supplementary material available at https://doi. org/10.1186/s12974-021-02122-1.

Additional file 1: Supplementary Figure 1. Association between in vivo hippocampal TSPO signals measured using ${ }^{18} \mathrm{~F}$-FEBMP-PET and inflammatory marker immunoreactivity. ${ }^{18}$ F-FEBMP-PET signals and immunoreactivity (IR) of TSPO (A), IBA-1 (B) and C1q (C).

\section{Acknowledgements}

The authors thank S. Uchida for technical support and assistance (National Institute of Radiological Sciences, NIRS), M.-R. Zhang for radiosynthesis (National Institute of Radiological Sciences), A.S.J Wyatt for assistance with statistical analysis (Hong Kong University of Science and Technology), and S. A. Herff for helpful feedback on the manuscript (EPFL).

\section{Authors' contributions}

$A M B, L H F, M H$, and NS designed the research; LHF, AMB, and NS performed the research; $L H F, A M B, N S$, and $M H$ analyzed the data; $L H F$ and AMB drafted the manuscript. All authors edited and approve the manuscript.

\section{Funding}

This research was supported by JSPS KAKENHI Grant Number 26830038 and Nanyang Assistant Professorship from Nanyang Technological University Singapore to $A M B$, and grant-in-aid for Brain Mapping by Integrated Neurotechnologies for Disease Studies (Brain/MINDS; JP19dm0207072) to MH from Japan Agency for Medical Research and Development to MH.

\section{Availability of data and materials}

The dataset(s) supporting the conclusions of this article are available in the Nanyang Technological University Institutional repository https://dr.ntu.edu. $\mathrm{sg} /$.

\section{Declarations}

Ethics approval and consent to participate

All animal experimentation was carried out in accordance with the recommendations in the Guide for the Care and Use of Laboratory Animals of the National Institutes of Health and was approved by the National Institutes for Quantum and Radiological Science and Technology (Japan) Institutional Animal Care and Use Committee.

Consent for publication

Not applicable.

Competing interests

The authors declare no competing interests.

Received: 22 December 2020 Accepted: 2 March 2021

Published online: 19 March 2021

References

1. Anderson MJ. Permutational multivariate analysis of variance (PERMANOVA). In: Balakrishnan N, Colton T, Everitt B, Piegorsch W, Ruggeri F, Teugels JL, editors. Wiley StatsRef: statistics reference online: Wiley; 2017. p. 1-15.

2. Arriagada PV, Growdon JH, Hedley-Whyte ET, Hyman BT. Neurofibrillary tangles but not senile plaques parallel duration and severity of Alzheimer's disease. Neurology. 1992;42(3 Pt 1):631-9. https://doi.org/10.1212/wnl.42.3. 631.

3. Asai H, Ikezu S, Tsunoda S, Medalla M, Luebke J, Haydar T, Wolozin B, Butovsky O, Kügler S, Ikezu T. Depletion of microglia and inhibition of exosome synthesis halt tau propagation. Nat Neurosci. 2015;18(11):1584-93. https://doi.org/10.1038/nn.4132.

4. Audrain M, Haure-Mirande J-V, Wang M, Kim SH, Fanutza T, Chakrabarty P, Fraser P, St George-Hyslop PH, Golde TE, Blitzer RD, Schadt EE, Zhang B, Ehrlich ME, Gandy S. Integrative approach to sporadic Alzheimer's disease: deficiency of TYROBP in a tauopathy mouse model reduces $\mathrm{C} 1 \mathrm{q}$ and normalizes clinical phenotype while increasing spread and state of phosphorylation of tau. Mol Psychiatry. 2019;24(9):1383-97. https://doi.org/1 0.1038/s41380-018-0258-3.

5. Banati RB, Middleton RJ, Chan R, Hatty CR, Kam WW, Quin C, et al. Positron emission tomography and functional characterization of a complete PBR/ TSPO knockout. Nat Commun. 2014;5(1):5452. https://doi.org/10.1038/ ncomms6452.

6. Barron AM, Garcia-Segura LM, Caruso D, Jayaraman A, Lee JW, Melcangi RC, Pike CJ. Ligand for translocator protein reverses pathology in a mouse model of Alzheimer's disease. J Neurosci. 2013;33(20):8891-7. https://doi. org/10.1523/JNEUROSCI.1350-13.2013.

7. Barron AM, Higuchi M, Hattori S, Kito S, Suhara T, Ji B. Regulation of anxiety and depression by mitochondrial translocator protein-mediated steroidogenesis: the role of neurons. Mol Neurobiol. 2020a;58(2):550-63. https://doi.org/10.1007/s12035-020-02136-5.

8. Barron AM, Ji B, Fujinaga M, Zhang M-R, Suhara T, Sahara N, Aoki I, Tsukada $\mathrm{H}$, Higuchi M. In vivo PET imaging of mitochondrial abnormalities in a mouse model of tauopathy. Neurobiol Aging. 2020b;94:140-8 https://doi. org/10.1016/j.neurobiolaging.2020.05.003.

9. Barron AM, Tokunaga M, Zhang MR, Ji B, Suhara T, Higuchi M. Assessment of neuroinflammation in a mouse model of obesity and beta-amyloidosis using PET. J Neuroinflammation. 2016;13(1):221. https://doi.org/10.1186/s12 974-016-0700-X

10. Bates D, Mächler M, Bolker B, Walker S. Fitting Linear Mixed-Effects Models Using Ime4. Journal of Statistical Software. 2015; 67(1):1-48. https://doi.org/1 0.18637/jss.V067.101.

11. Bennett RE, Bryant A, Hu M, Robbins AB, Hopp SC, Hyman BT. Partial reduction of microglia does not affect tau pathology in aged mice. J Neuroinflammation. 2018;15(1):311. https://doi.org/10.1186/s12974-018-134 8-5.

12. Blackmore T, Meftah S, Murray TK, Craig PJ, Blockeel A, Phillips K, Eastwood B, O'Neill MJ, Marston H, Ahmed Z, Gilmour G, Gastambide F. Tracking 
progressive pathological and functional decline in the rTg4510 mouse model of tauopathy. Alzheimers Res Ther. 2017;9(1):77. https://doi.org/10.11 86/s13195-017-0306-2.

13. Braak H, Braak E. Neuropathological stageing of Alzheimer-related changes. Acta Neuropathol. 1991;82(4):239-59. https://doi.org/10.1007/bf00308809.

14. Choi HB, Khoo C, Ryu JK, van Breemen E, Kim SU, McLarnon JG. Inhibition of lipopolysaccharide-induced cyclooxygenase-2, tumor necrosis factor-alpha and [Ca2+]i responses in human microglia by the peripheral benzodiazepine receptor ligand PK11195. J Neurochem. 2002;83(3):546-55 https://doi.org/10.1046/j.1471-4159.2002.01122.x.

15. Choi J, Ifuku M, Noda M, Guilarte TR. Translocator protein (18 kDa)/ peripheral benzodiazepine receptor specific ligands induce microglia functions consistent with an activated state. Glia. 2011;59(2):219-30. https:// doi.org/10.1002/glia.21091

16. Christensen A, Pike CJ. TSPO ligand PK11195 improves Alzheimer-related outcomes in aged female 3xTg-AD mice. Neurosci Lett. 2018;683:7-12. https://doi.org/10.1016/j.neulet.2018.06.029.

17. Comes G, Manso Y, Escrig A, Fernandez-Gayol O, Sanchis P, Molinero A, Giralt M, Carrasco J, Hidalgo J. Influence of transgenic metallothionein-1 on gliosis, CA1 neuronal loss, and brain metal levels of the Tg2576 mouse model of Alzheimer's disease. Int J Mol Sci. 2017;18(2). https://doi.org/10.33 90/ijms18020251.

18. Cosenza-Nashat M, Zhao ML, Suh HS, Morgan J, Natividad R, Morgello S, Lee SC. Expression of the translocator protein of $18 \mathrm{kDa}$ by microglia, macrophages and astrocytes based on immunohistochemical localization in abnormal human brain. Neuropathol Appl Neurobiol. 2009;35(3):306-28. https://doi.org/10.1111/j.1365-2990.2008.01006.x.

19. Farber K, Cheung G, Mitchell D, Wallis R, Weihe E, Schwaeble W, Kettenmann $\mathrm{H}$. C1q, the recognition subcomponent of the classical pathway of complement, drives microglial activation. J Neurosci Res. 2009; 87(3):644-52. https://doi.org/10.1002/jnr.21875.

20. Fonseca MI, Chu SH, Hernandez MX, Fang MJ, Modarresi L, Selvan P, MacGregor GR, Tenner AJ. Cell-specific deletion of C1qa identifies microglia as the dominant source of C1q in mouse brain. J Neuroinflammation. 2017; 14(1):48. https://doi.org/10.1186/s12974-017-0814-9.

21. Fonseca Ml, Zhou J, Botto M, Tenner AJ. Absence of C1q leads to less neuropathology in transgenic mouse models of Alzheimer's disease. J Neurosci. 2004;24(29):6457-65. https://doi.org/10.1523/JNEUROSCI.0901-04.2 004.

22. Gamache J, Benzow K, Forster C, Kemper L, Hlynialuk C, Furrow E, Ashe KH, Koob MD. Factors other than hTau overexpression that contribute to tauopathy-like phenotype in rTg4510 mice. Nat Commun. 2019;10(1):2479. https://doi.org/10.1038/s41467-019-10428-1.

23. Gong J, Szego EM, Leonov A, Benito E, Becker S, Fischer A, Zweckstetter M, Outeiro T, Schneider A. Translocator protein ligand protects against neurodegeneration in the MPTP mouse model of parkinsonism. J Neurosci. 2019;39(19):3752-69. https://doi.org/10.1523/JNEUROSCI.2070-18.2019.

24. Grimm A, Lejri I, Halle F, Schmitt M, Gotz J, Bihel F, Eckert A. Mitochondria modulatory effects of new TSPO ligands in a cellular model of tauopathies. J Neuroendocrinol. 2020;32(1):e12796. https://doi.org/10.1111/jne.12796.

25. Gulyas B, Makkai B, Kasa P, Gulya K, Bakota L, Varszegi S, et al. A comparative autoradiography study in post mortem whole hemisphere human brain slices taken from Alzheimer patients and age-matched controls using two radiolabelled DAA1106 analogues with high affinity to the peripheral benzodiazepine receptor (PBR) system. Neurochem Int. 2009;54(1):28-36. https://doi.org/10.1016/j.neuint.2008.10.001.

26. Ishikawa A, Tokunaga M, Maeda J, Minamihisamatsu T, Shimojo M, Takuwa H, Ono M, Ni R, Hirano S, Kuwabara S, Ji B, Zhang MR, Aoki I, Suhara T, Higuchi M, Sahara N. In vivo visualization of tau accumulation, microglial activation, and brain atrophy in a mouse model of tauopathy rTg4510. J Alzheimers Dis. 2018;61(3):1037-52. https://doi.org/10.3233/JAD-170509.

27. Ittner LM, Götz J. Amyloid- $\beta$ and tau--a toxic pas de deux in Alzheimer's disease. Nat Rev Neurosci. 2011;12(2):65-72. https://doi.org/10.1038/nrn2967.

28. Ji B, Maeda J, Sawada M, Ono M, Okauchi T, Inaji M, Zhang MR, Suzuki K Ando K, Staufenbiel M, Trojanowski JQ, Lee VMY, Higuchi M, Suhara T. Imaging of peripheral benzodiazepine receptor expression as biomarkers of detrimental versus beneficial glial responses in mouse models of Alzheimer's and other CNS pathologies. J Neurosci. 2008;28(47):12255-67. https://doi.org/10.1523/JNEUROSCI.2312-08.2008.

29. Karlstetter M, Nothdurfter C, Aslanidis A, Moeller K, Horn F, Scholz R, Neumann H, Weber BHF, Rupprecht R, Langmann T. Translocator protein
$(18 \mathrm{kDa})(\mathrm{TSPO})$ is expressed in reactive retinal microglia and modulates microglial inflammation and phagocytosis. J Neuroinflammation. 2014;11(1): 3. https://doi.org/10.1186/1742-2094-11-3.

30. Keren-Shaul H, Kenigsberg E, Jaitin DA, David E, Paul F, Tanay A, Amit I. MARS-seq2.0: an experimental and analytical pipeline for indexed sorting combined with single-cell RNA sequencing. Nat Protoc. 2019;14(6):1841-62. https://doi.org/10.1038/s41596-019-0164-4.

31. Lejri I, Grimm A, Halle F, Abarghaz M, Klein C, Maitre M, et al. TSPO ligands boost mitochondrial function and pregnenolone synthesis. J Alzheimers Dis. 2019;72(4):1045-58. https://doi.org/10.3233/JAD-190127.

32. $M a ~ L$, Zhang $H$, Liu $N$, Wang $P Q$, Guo WZ, Fu Q, Jiao LB, Ma YQ, Mi WD. TSPO ligand PK11195 alleviates neuroinflammation and beta-amyloid generation induced by systemic LPS administration. Brain Res Bull. 2016;121: 192-200. https://doi.org/10.1016/j.brainresbull.2016.02.001.

33. Maeda J, Zhang MR, Okauchi T, Ji B, Ono M, Hattori S, Kumata K, Iwata N, Saido TC, Trojanowski JQ, Lee VMY, Staufenbiel M, Tomiyama T, Mori H, Fukumura T, Suhara T, Higuchi M. In vivo positron emission tomographic imaging of glial responses to amyloid-beta and tau pathologies in mouse models of Alzheimer's disease and related disorders. J Neurosci. 2011;31(12): 4720-30. https://doi.org/10.1523/JNEUROSCI.3076-10.2011.

34. Maruyama M, Shimada H, Suhara T, Shinotoh H, Ji B, Maeda J, Zhang MR, Trojanowski JQ, Lee VMY, Ono M, Masamoto K, Takano H, Sahara N, Iwata N Okamura N, Furumoto S, Kudo Y, Chang Q, Saido TC, Takashima A, Lewis J, Jang MK, Aoki I, Ito H, Higuchi M. Imaging of tau pathology in a tauopathy mouse model and in Alzheimer patients compared to normal controls. Neuron. 2013;79(6):1094-108. https://doi.org/10.1016/j.neuron.2013.07.037.

35. Mietelska-Porowska A, Wasik U, Goras M, Filipek A, Niewiadomska G. Tau protein modifications and interactions: their role in function and dysfunction. Int J Mol Sci. 2014;15(3):4671-713. https://doi.org/10.3390/ijms15034671.

36. Notter T, Schalbetter SM, Clifton NE, Mattei D, Richetto J, Thomas K, Meyer U, Hall J. Neuronal activity increases translocator protein (TSPO) levels. Mol Psychiatry. 2020. https://doi.org/10.1038/s41380-020-0745-1.

37. Ramsden M, Kotilinek L, Forster C, Paulson J, McGowan E, SantaCruz K, Guimaraes A, Yue M, Lewis J, Carlson G, Hutton M, Ashe KH. Agedependent neurofibrillary tangle formation, neuron loss, and memory impairment in a mouse model of human tauopathy (P301L). J Neurosci. 2005;25(46):10637-247. https://doi.org/10.1523/JNEUROSCI.3279-05.2005.

38. Rodriguez-Martin T, Cuchillo-lbanez I, Noble W, Nyenya F, Anderton BH, Hanger DP. Tau phosphorylation affects its axonal transport and degradation. Neurobiol Aging. 2013;34(9):2146-57. https://doi.org/10.1016/j. neurobiolaging.2013.03.015.

39. R Core Team. R: A Language and Environment for Statistical Computing [Internet]. Vienna; 2016. Available from: https://www.R-project.org/.

40. Rupprecht R, Papadopoulos V, Rammes G, Baghai TC, Fan J, Akula N, Groyer G, Adams D, Schumacher M. Translocator protein (18 kDa) (TSPO) as a therapeutic target for neurological and psychiatric disorders. Nat Rev Drug Discov. 2010;9(12):971-88. https://doi.org/10.1038/nrd3295.

41. Santacruz K, Lewis J, Spires T, Paulson J, Kotilinek L, Ingelsson M, Guimaraes A, DeTure M, Ramsden M, McGowan E, Forster C, Yue M, Orne J, Janus C, Mariash A, Kuskowski M, Hyman B, Hutton M, Ashe KH. Tau suppression in a neurodegenerative mouse model improves memory function. Science. 2005;309(5733):476-81. https://doi.org/10.1126/science.1113694.

42. Sahara N, DeTure M, Ren Y, Ebrahim AS, Kang D, Knight J, Volbracht C, Pedersen JT, Dickson DW, Yen SH, Lewis J. Characteristics of TBS-extractable hyperphosphorylated tau species: aggregation intermediates in rTg4510 mouse brain. J Alzheimers Dis. 2013;33(1):249-63. https://doi.org/10.3233/JA D-2012-121093.

43. Scholz R, Caramoy A, Bhuckory MB, Rashid K, Chen M, Xu H, Grimm C, Langmann T. Targeting translocator protein (18 kDa) (TSPO) dampens proinflammatory microglia reactivity in the retina and protects from degeneration. J Neuroinflammation. 2015;12(1):201. https://doi.org/10.1186/ s12974-015-0422-5.

44. Shi Y, Manis M, Long J, Wang K, Sullivan PM, Remolina Serrano J, Hoyle R, Holtzman DM. Microglia drive APOE-dependent neurodegeneration in a tauopathy mouse model. J Exp Med. 2019;216(11):2546-61. https://doi.org/1 0.1084/jem.20190980.

45. Tiwari AK, Ji B, Yui J, Fujinaga M, Yamasaki T, Xie L, Luo R, Shimoda Y, Kumata K, Zhang Y, Hatori A, Maeda J, Higuchi M, Wang F, Zhang MR. [18F]FEBMP: positron emission tomography imaging of TSPO in a model of neuroinflammation in rats, and in vitro autoradiograms of the human brain. Theranostics. 2015;5(9):961-9. https://doi.org/10.7150/thno.12027. 
46. Torres SR, Frode TS, Nardi GM, Vita N, Reeb R, Ferrara P, et al. Antiinflammatory effects of peripheral benzodiazepine receptor ligands in two mouse models of inflammation. Eur J Pharmacol. 2000;408(2):199-211. https://doi.org/10.1016/S0014-2999(00)00760-3.

47. Tsukada H, Nishiyama S, Fukumoto D, Kanazawa M, Harada N. Novel PET probes 18F-BCPP-EF and 18F-BCPP-BF for mitochondrial complex I: a PET study in comparison with 18F-BMS-747158-02 in rat brain. J Nucl Med. 2014; 55(3):473-80. https://doi.org/10.2967/jnumed.113.125328.

48. Zhang B, Gaiteri C, Bodea L-G, Wang Z, McElwee J, Podtelezhnikov AA, Zhang C, Xie T, Tran L, Dobrin R, Fluder E, Clurman B, Melquist S, Narayanan M, Suver C, Shah H, Mahajan M, Gillis T, Mysore J, MacDonald ME, Lamb JR, Bennett DA, Molony C, Stone DJ, Gudnason V, Myers AJ, Schadt EE, Neumann H, Zhu J, Emilsson V. Integrated systems approach identifies genetic nodes and networks in late-onset Alzheimer's disease. Cell. 2013; 153(3):707-20. https://doi.org/10.1016/j.cell.2013.03.030.

\section{Publisher's Note}

Springer Nature remains neutral with regard to jurisdictional claims in published maps and institutional affiliations.

Ready to submit your research? Choose BMC and benefit from:

- fast, convenient online submission

- thorough peer review by experienced researchers in your field

- rapid publication on acceptance

- support for research data, including large and complex data types

- gold Open Access which fosters wider collaboration and increased citations

- maximum visibility for your research: over $100 \mathrm{M}$ website views per year

At $\mathrm{BMC}$, research is always in progress.

Learn more biomedcentral.com/submissions 